\title{
Turizm İşletmelerinde Fiyatlandırma Stratejileri ve Muhasebe Bilgi Kalitesi İlişkisi ${ }^{1}$
}

\author{
DOI: 10.26466/opus.796496
}

*

\author{
Murat Karahan * \\ * Dr. Öğr. Üyesi, Gaziantep Üniversitesi, İ̈BF, İşletme Bölümü, Gaziantep/Türkiye \\ E-Posta: karahan@gantep.edu.tr \\ ORCID: $\underline{0000-0002-5066-4257}$

\section{$\ddot{O} z$}

İşletmelerin küresel rekabet ortamında uzun süre varlığını sürdürebilmesi için pazarlama faaliyetlerinin stratejik anlamda ve yeterli seviyede gerçekleştirilmesi kaçınılmaz bir hal almaktadır. Bu durumun beraberinde getirdiği zorunluluk bilgi temelli rekabetin önemli hale geldiğ i bu zamanda işletmelerin yenilikçi bir politika ve yeni stratejiler oluşturmasina sebebiyet vermektedir. Bunun gerçekleştirilmesi, güvenilir, uygulanabilir ve zamanlama açıcından yerinde bir bilgi ile mümkün hale gelmektedir. Bu nitelikleri bünyesinde barındirmayan bilgiler stratejik anlamda hata oranı yüksek kararlarm verilmesine neden olmaktadir. Bu sebeplerden dolayı, eksik ve hatalı bilgilerle alınan yanlış kararların neden olduğ u sorunların kısa vadeli pazarlama önlemleriyle çözülememesi, stratejik pazarlamada bilginin yönetilmesini ve daha etkin kullanılmasım önemli hale getirmektedir. Gelişmiş ya da gelişmekte olan ekonomilerde temel girdi olarak kullanulan bilgi, günümüz organizasyonların en temel kaynă̆ını oluşturmaktadır. Ekonomik değere sahip olan işletmeler, amaçlarına ulaşabilmek için bilgiye ihtiyaç duymaktadır. Muhasebe Bilgi Sistemi (MBS), işletme süreçlerinin muhasebe yönünü yansıtmaktadır. Muhasebe Bilgi Sistemi (MBS), işletme faaliyetleri ile ilgili verilerin toplandığı, kayıt altına alındı̆̆g, verileri bilgiye dönüştürerek iç ve dış bilgi kullanıcılarına ihtiyaç duydukları bilgileri kaliteli bir şekilde sağlamaya çalışan bir işletme bilgi sistemi olarak ifade edilebilmektedir. Bir pazarlama karması elemanı olan fiyat, önemli bir rekabet aracı olmakla birlikte, turizm sektöründe fiyatlandırma stratejisinin ve buna uygun fiyat düzeyinin belirlenmesi, turizm işletmesinin iş hacmini etkilemektedir. Turizm işletmelerinde fiyatlandırma, işletmenin hedefleri doğrultusunda belirlenmektedir. Fiyatlandırmadaki amaç turizm işletmesinin pazarlama planlamasının bir parçasın oluşturmaktadır.Araştırma amaç, turizm işletmeleri açısından fiyatlandırmanın önemi ve muhasebe bilgi kalitesi ile ilişkisi incelenmektedir. Bu çalışma sonucunda, pazarlama politikalarından fiyatlandırma stratejileri ile muhasebe bilgi kalitesinin birbirinden etkilendiği ve bir bütün olarak ele alınması gerektiği ifade edilmektedir.

Anahtar Kelimeler: Muhasebe, Muhasebe Bilgi Kalitesi, Bilgi Kalitesi, Fiyatlandirma Stratejileri, Turizm İşletmeleri

\footnotetext{
${ }^{1}$ Bu çalışma, Murat Karahan'ın 2014 yılında sunulan "Turizm Sektöründe Fiyatlandırma Stratejilerinin incelenmesi: Güneydoğu Anadolu Bölgesi Örneği" isimli doktora tezinden yararlanılarak yapılmıştır
} 


\title{
The Relationship between Pricing Strategies and Accounting Information Quality in Tourism Enterprises
}

\begin{abstract}
For businesses to survive in a globally competitive environment for longer time, marketing activities are inevitably carried out strategically and at a sufficient level. In today's world where knowledge-based competition keenly prevalent, this situation causes the enterprises to develop new policies and strategies. And this can be made with reliable, appropriate and timely information. Information which does not contain these qualities can cause strategically wrong decisions. Therefore, the problems which caused by wrong decisions due to missing and incorrect information cannot be solved with short-term marketing measures. Hence, it is important to manage and use information more effectively in strategic marketing. Information, which is used as a basic input in developed or developing economies, is the main source of organizations nowadays. Businesses with economic value need the information to achieve their goals. Accounting Information System (AIS) reflects the accounting aspect of business processes. Accounting Information System (AIS) can be expressed as a business information system that collects and records the data related to business activities and tries to provide the information they need to the internal and external information users in a quality manner by transforming the data into information.

Price, which is a marketing mix element, is also a vital competitive tool, but determining the pricing strategy and the appropriate price level in the tourism sector affects the business volume of the tourism business. Pricing in tourism businesses is determined in line with the objectives of the business. The purpose of pricing is part of the marketing planning of the tourism business.

The aim of this research is the importance of pricing in terms of tourism businesses and their relationship with accounting information quality. The result of this study stated that pricing strategies and accounting information quality are affected by each other and should be handled as a whole.
\end{abstract}

Keywords: Accounting, Accounting Information Quality, Information Quality, Pricing Strategies, Tourism Enterprises 


\section{Giriş}

Modern manada işletmeler kompleks bir yapıya sahip olmakta ve muhasebe, finans, ürün üretimi, insan kaynakları, mühendislik çalışmaları, bilgi teknolojileri, ürünün satışı, pazarlama ve yönetimsel anlamda etkili fonksiyonel departmanlarda faaliyetlerini sürdürebilmek çalışan personeller bulundurmaktadır. Bu gibi işletmelerde planlamanın, koordinasyonun ve kontrolün sağlanması için bilgiyi üreten kullanıcılara ulaştıran ana bilgi sistemlerinin bulunduğu bilinmektedir. Bu sistemlerden biri olan Muhasebe Bilgi Sistemi (MBS), işletmelerde amaçlara ulaşılabilmesi amacıyla gereken işlemlerin yerinde ve zamanında yapılmasında büyük bir öneme sahiptir. (Doğan vd., 2004). Gelişmiş ya da gelişmekte olan ekonomilerde temel girdi olarak kullanılan bilgi, günümüz organizasyonların en temel kaynağını oluşturmaktadır (Drucker, 1992). Ekonomik değerli olan işletmelerin, amaçların gerçekleştirmek için doğru ve güvenilir bir bilgi gereksinimleri vardır. MBS, işletme süreçlerinin muhasebe yönünü yansıtmaktadır. MBS, işletmenin faaliyetleriyle alakalı verilerin toparlandığı, kayıtlandığı, verilerin bilgilere dönüştürülerek içteki ve dıştaki bilgi yorumlayıcılarına ihtiyaçları olan kalitedeki verileri ulaştıran sistem olarak ifade edilebilmektedir (Romney vd., 1997).

Yönetim etkinliğinin kontrolü, yatırımların seçimi, muhasebe, tedarik, finans, üretim, pazarlama ve bilgi teknolojileri planlarının yapılması ile işletme sonuçlarının tartışılmasında MBS'nin elde ettiği bilgilerden önemli ölçüde faydalanılmaktadır. MBS, izlemeye, programlamaya, teşhis etmeye ve önlem almaya yönelik bilgilerin temel kaynağını oluşturmaktadır. Bu nedenle fonksiyonel açıdan muhasebe, yaptığı işlemler ile işletmelerin birer görme organını oluşturmaktadır (Acar ve Tetik, 2005). Muhasebe Bilgi Sistemi, "finansal muhasebenin, maliyet muhasebesinin, sorumluluk muhasebesinin, nakitlerin ve sermayelerin bütçelenmesinin, işletmeninin varlıklarını, borçlarını, sermayesini, gelirlerini ve giderlerini mali nitelikli tarihsel geçmişini ve geleceğe yönelik bilgilerini oluşmasına kaynaklık eden bir bilgiler sistemi" olarak tanımlanabilmektedir (Sürmeli vd., 2006).

Muhasebe verileri, işletmelerin finansal manada işlemlerinin gerçekleşmesini, belgelerle kayıt edilmesi, tasnif edilmesi ve raporlandırılması işlemleri ve bu işlemlerin birleşimi olan muhasebeleştirme süreci sonucunda finansal tablolar farklı hesaplar içinde özet olarak verilen sayıların kıyaslanması ve 
yorumu neticesinde elde edilen işletmeye yönelik yargılardır. Muhasebeleşmiş bilgilerin çok olmasının aksine bu bilgilerin kaliteli olmaları beklenmektedir. Bu durumda muhasebede bilginin kaliteli olmasının gerekliliğini ortaya çıkarmaktadır.

Muhasebenin kalitesinin, finansal raporlamanın kalitesinin, finansal bilgininin kalitesinin ve muhasebe bilgisinin kalitesinin anlamsal olarak birbirine benzer olduğu bilinmektedir. (Verdi, 2006; Beatty vd., 2010; Callen vd., 2013; Gençoğlu ve Ertan, 2012) Bu çalışmada muhasebede bilginin kalitesi ifadesini kullandık.

Muhasebe bilgi kalitesi, "işletmelerin cari faaliyetlerinde başarı-başarısızlık durumunun tam manasıyla ele alan kapsamı geniş olan muhasebe bilgileri" olarak ifade edilerek elde edilen bilginin "işletmelerin gelecekteki performansların tahmini için kullanmaya elverişli ve işletmelerin değerlerinin hesaplanmasına yardım" etmesi gerekliliği şeklinde belirtilmektedir (Dechow ve Schrand, 2004; Hribar vd, 2014:511; Callen vd., 2013). Yapılan tanımların ışığında finansal tabloların şeffaflığının, kabul edilebilirliğinin, güvenilirliğinin ve işletmenin finansal tablolarından yararlanılarak verilen ekonomik anlamdaki kararlar bilginin kullanıcısının elde edeceği faydalar üzerinde durulmaktadır. (Hribar vd, 2014, s.511). Diğer bir tanımda ise, muhasebenin kalitesinin, muhasebenin bilgi kalitesinin berzer olarak kullanan bu kavram "işletmelere sermaye kaynağı oluşturan yatırımcının ilerleyen dönemlerdeki nakit akışı hakkında finansal tabloların vasıtasıyla açıkça bilgilendirme" olarak tanımlanmaktadır (Callen vd., 2013). Pounder (2013:18) ise, literatürde kavramsallaşmış tanımların ortak özellikleri "finansal tabloların kullanıcılarının da muhasebe bilgileri ve gösterdiği gerçek değerlere göre bu bilgilerin değerlendirmesinin sağlanması" şeklinde ifade etmektedir.

Nitekim "Türkiye Muhasebe Standartları (TMS)" / "Türkiye Finansal Raporlama Standartları (TFRS)'nin Finansal Raporlamalarla alakalı Kavramsal Çerçevede "finansal tablolarla elde edilen muhasebe bilgilerinin fayda sağlayabilmesi amaciyla bulunması gerekli olan özellikler" ortaya konularak muhasebe bilgisinin kaliteli olmasına vurgulama yapılmakta. Kavramsallaşmış anlamda temel niteliksel özellik olarak gösterilen, faydalı bir finansal bilginin, bilgi kullanıcılarının ihtiyacına uygun ve açıklanması amaçlanan konunun gerçeğe uygun bir şekilde sunulması gerekmektedir. İhtiyaca uygunluk, finansal bilginin kullanıcılar tarafından verilen kararları etkileme gücüne sahip 
olmak şeklinde belirtilirken, gerçeğe uygunluk ise açıklanmasının amaca uygun ve gerçeklikle uyumlu olarak sunulması olarak ifade edilmektedir. Destekleyici niteliksel özellikler olarak, finansal bilgilerin karşılaştırılabilir, doğrulanabilir, zamanında sunum ve anlaşılabilir olması gerekmektedir. Karşılaştırılabilirlik ise, "raporlanan işletmelerle alakalı bilginin farklı işletmelerle benzer bilgilere ve aynı işletmenin farklı dönemine ya da farklı tarihlerine ait benzer olan bilgilerin karşılaştırılabilirliği" şeklinde ifade edilmektedir. Doğrulanabilirlik ise, "ayrı bilgi düzeylerindeki bağımsız gözlemciler ve açıklamalarının doğruluğu konusundaki birliğin sağlanması" olarak tanımlanmaktadır. Zamanında sunum, "bilginin, karar verenler açısından kararlarını etkileyebileceği zamanda mevcut olması" şeklinde belirtilmektedir. Anlaşılabilirlik ise "bilginin açı ve öz olarak sınıflandırılması, tanımlanması ve sunulması" gerektiği vurgulanmaktadır. Bu özellikler sayesinde bilgilerin faydalarının arttırılabileceği sonucuna varılmaktadır. (http://www.kgk.gov.tr/).

Muhasebede bilginin kaliteli olmasın belirleyen özelliklerin geniş manada sıralanması şöyledir (Wang ve Strong, 1996):

- İhtiyaca Uygunluk: Alınan ekonomik kararlarla muhasebeleşmiş bilgilerin uyuşması ve kararlar için bilgiler elde edinilmesidir. Gerçeğe uygunluk: Muhasebeleşmiş bilgilerin işletmelerin reel pozisyonunu, ekonomik gerçeklikleri, risk faktörlerini ve getirilerinin uygun ve detaylı yansıtılabilmesini ifade eder.

- Karşılaştırılabilirlik: Muhasebedeki politikaların dönemsel olarak tutarlı olması, muhasebeleşmiş bilgilerin yerine ikame edilebilen politikalarla ya da ayrı dönemlerde kullanılan muhasebe uygulamaları ile uygun olarak ilişkilendirilebilmesidir.

- Doğrulanabilirlik: Muhasebeleşmiş bilgilerin somut verilerle desteklenmesi, değerlendirme ölçütlerinin ve esaslarının reel bir özellik taşımasıdir.

- Zamanlılık: Muhasebeleşmiş bilgilerin ihtiyaca uygun zamanlarda ulaşlabilmesi ve ileriki dönemlere ilişkin karar mekanizmalarında uygulanabilmesidir.

- Anlaşılabilirlik: Finansal tablodaki muhasebeleşmiş bilgilerin, bunu kullananların kolaylıkla kavrayabileceği özellikte olmasını ifade etmektedir.

- Ilgililik: Muhasebeleşmiş bilgilerin işletmelerde alınacak ekonomik kararlara güçlü olarak etkilemesidir. 
- Güvenilirlik: Muhasebeleşmiş verilerin hatalı olmaması ve hileli verilerden ayırt edilmiş olmasıdır.

- Yararlılık: Muhasebeleşmiş bilgilerin, kullanıcılara kararları konusunda faydalı olmasidir.

- Ulaşılabilirlik: Muhasebeleşmiş bilgiye ulaşma giderlerinin o bilginin faydasından çok olmamasıdır.

- Bütünlük: Bilgi eksik olmamalıdır.

- Öz temsil: Bilgi bütünü temsil edebilmelidir.

- Tutarlılık: Bilgi ayn formatta hazırlanmalıdır.

- Kolay Elde edilebilirlik: Bilgi kolay üretilebilmeli ve farklı işlemlerde uygulanabilmelidir.

- Hatasız: Bilgi doğru ve güvenilir olmalıdır.

- Geçerlilik: Bilgi, kavramlarının kaynak ya da içerikleri çok geçerli olmalidir.

- Katma değer: Bilgi kullanımında faydalı olmalı ve avantaj sağlamalıdır.

İşletmelerde muhasebe faaliyetleri birçok faktörün tesirindedir. Faktörlerin çokluğu çeşitliliği muhasebeleşmiş bilginin nitelikli veya niteliksiz olmasına yol açabilmektedir. Muhasebede bilginin kaliteli olmasını sağlayan durumlar aşağıdaki başlıklar altında ele alınmaktadır. (Gençoğlu ve Ertan (2012);

- Muhasebedeki Uygulamalarn: Genelleşmiş yani herkes tarafından kabul görmüş muhasebe ilkeleri veya uluslararası belirlenmiş standartlara bakılarak hazırlanan değişik uygulamalar muhasebede bilginin kaliteli olmasını etkilemektedir.

- Ülkelerarasındaki Farklılıklar: Ülkelerin yasal politikaları ve sistem işleyişleri, finansal piyasalardaki gelişmişlikleri, vergilendirme politikaları, kültürel yapıları, ekonomik etkenleri, muhasebenin mesleki anlamda ülkedeki alt yapısı ve mesleğin değeri muhasebedeki bilginin kalitesinin etkilenmesine neden olmaktadır.

- Issletmelere Özgülenmiş Faktörler: İşletmenin boyutu, işletmenin sermayelerindeki yapı, finansal tabloları denetlenmesinde denetimi yapan firmanın kalitesi, yabancı menkul kıymet borsalarında kote olması durumları, işletmenin kurumsallaşmış yönetim yapıları gibi faktörler muhasebede bilginin kalitesinin etkilenmesine neden olmaktadır. 
Muhasebede bilginin kaliteli olması finansal tablolar ile elde edilen verilerin reel ve gerçekçi olarak hazırlanmasının bir neticesidir. Finansal tabloların güvenilirliği, muhasebe ana ilkelerine ve kurallarına riayet edilmesi, etkili muhasebenin ve işletme içi kontrollerin etkin olarak kullanılması, finansal tabloların bağımsız bir denetim sürecinden geçirilmesi gibi faktörlerin uygulanmasıyla elde edilmektedir. Ancak faaliyette bulunulan ülkeye özgü bazı uygulamalar uluslararası boyut kazanmaması nedeniyle finansal tablo güvenilirliğini azaltabilmektedir. Ayrıca finansal raporlamada halka açık olan anonim şirketlerin, finans kuruluşlarının ve diğer işletmeleri açısından ele alındığında T.C. Maliye Bakanlığı, Sermaye Piyasası Kurulu (SPK), Bankacılık Düzenleme ve Denetleme Kurumu (BDDK) gibi kurumların çıkardıkları tebliğlerin finansal raporlamada çok başlılığa neden olduğu ifade edilmektedir. Buna ek olarak Türkiye' deki kayıt dışı ekonominin varlığının ve büyüklüğünün, işletmelerinin ancak kayıt altına alınmış olan değerlerini raporladıkları ve finansal tablolarının kayıt dışı işlemlerin asla yansıtmamasından dolayı finansal tablo kullanıcılarının güven algısını olumsuz yönde etkilediği ve bunun güvenilirliği azaltacağı ifade edilebilir.

\section{Materyal ve Yöntem}

Bu çalışmada, turizmdeki fiyatlama stratejileri ile muhasebe bilgi kalitesi arasındaki ilişkiye kavramsal olarak değinilmiştir.

\section{Turizm İşletmeleri ve Fiyatlandırma Stratejileri}

İşletmelerin, pazarlama amaçları doğrultusunda fiyatlandırma stratejilerini uygulama açısından en uygun yol/yolları seçmeleri gerekmektedir. Gelişen pazar hacmine paralel olarak turizm pazarlamasında rekabetin yoğunlaşması vb. gibi nedenlerle fiyatlandırma stratejilerinin geleneksel stratejiler olan maliyete dayalı, talebe dayalı stratejilere oranla oldukça dinamik ve farklılaştırılmış olması zorunluluğu doğmaktadır. Turizm pazarlamasında fiyatlandırma stratejilerinin uygulanması esnasında seçilen yol ve uygulama biçimlerinin turizm ürününün değeri açısından da değerlendirilmesine ihtiyaç vardır. Günümüzde de tüketicilerin satın alma kararlarında temel bir belirleyici, fiyat olmaktadır. Son yıllarda fiyat dışındaki faktörlerden ürünün imajı gibi unsurların tüketicilerin satın alma kararlarındaki etkisi hızla artmaya 
başlasa da, fiyatlandırma kararları, halen işletmelerin pazar paylarını ve karlılıklarını belirleyen temel faktörler arasında yer almaktadır (Kwapil vd., 2005, s.23). İşletmeler açısından en optimal karı gerçekleştirmeye yönelik izlenecek yol, fiyatlandırma kararlarının doğruluğundan geçmektedir (Artar, 1999, s.11).

Bir pazarlama karması elemanı olan fiyat, önemli bir rekabet aracı olmakla birlikte, turizm sektöründe fiyatlandırma stratejisinin ve buna uygun fiyat düzeyinin belirlenmesi, turizm işletmesinin iş hacmini etkilemektedir. Pazar talebini, maliyet yapısını ve rakiplerin fiyatlarını belirleyen turizm işletmesi, fiyatlandırma stratejilerinden birini kullanarak, ürününü hangi fiyat ile turizm pazarına sunacağına karar vermektedir (Yükselen, 2010, s.271). Turizm işletmesinin ürettiği mal ve hizmetler için uygun düzeyde kar elde etmesini sağlayabilecek bir fiyat düzeyi belirlemesi ve uygulaması gerekmektedir. Uygulanacak fiyat aralığı, işletmenin ne zarar etmesini ne de talebi engelleyecek düzeyde olmalıdır. Kotler, 3C yaklaşımı ile bu fiyat düzeyinin çerçevesini çizmektedir. Turizm ürününün fiyatı, $3 C$ yaklaşımına göre çizilen bu fiyat çerçevesi içerisinde en düşük fiyat ile en yüksek fiyat arasında belirlenmektedir (Kotler, 2003a, s.513).

- Maliyet (Cost)

- Rakiplerin ve ikame ürünlerin fiyatı (Competitors' and prices of substitutes)

- Müşterilerin değer algılamaları (Customers' perceptions of value)

Turizm işletmelerinde fiyatlandırma, işletmenin hedefleri doğrultusunda belirlenmektedir. Fiyatlandırmadaki amaç turizm işletmesinin pazarlama planlamasının bir parçasını oluşturmaktadır. Genel fiyatlandırma amaçlarının yanı sıra turizm işletmelerinin özelliklerini dikkate alan fiyatlandırma amaçları ise şu şekilde sıralanmaktadır (Rızaoğlu, 2004, s.197-198):

- Rekabet Edebilmek

- Kazanç (Kar) Sağlamak

- Hazırdaki Durumunu Korumak

- Pazara Nüfuz Etmek

- Savunmak

Turizm işletmelerinde, hedef ve amaçlara uygun fiyatlandırma stratejileri belirlenmektedir. Fiyat stratejileri açısından; pazarın kaymağının alınması ve pazara nüfuz stratejisi gibi farklı durumlar uygulanabilir. Pazarın kaymağı- 
nın alınması fiyatlandırma stratejisinde, turizm pazarlarına üst aralıktaki fiyatlardan girilir. Bu strateji, taleplerin kuvvetli olması halinde ve turizmdeki ürünlerin çokça farklılaştırılması durumunda uygulanabilmesi söz konusudur (Lamb vd., 1994:84). Pazara nüfuz etme fiyatlandırma stratejisinde turizm işletmeleri, pazardaki rakiplerinin altında bir fiyat belirleyip pazar bölümlerinde kısa zaman zarfında söz sahibi olmayı amaçlamaktadır. (Friel, 1999, s.101). Bu strateji için, tüketicilerin fiyatlara karşı duyarlı olmadır. Talep fiyatlandırmaya karşı hassas olmaması durumunda düşük fiyatlandırma talepte artışa neden olmayacaktır. (Baker vd., 1998, s.83).

En düşük fiyat noktası, işletmenin kar etme olasılığının olmadığı noktayı, en yüksek fiyat noktası ise turizm ürününü pazarlamanın mümkün olmadığı noktayı ifade etmektedir. Fiyat düzeyini belirlemek için turizm işletmelerinin uygulayabilecekleri temel fiyatlandırma stratejileri mevcuttur. Turizm işletmeleri ürüne ve pazara bağlı olarak fiyatlandırma stratejilerinden birini veya birkaçın bir arada uygulamaktadırlar. Bu stratejiler, maliyete dayalı, talebe dayalı, rekabete dayalı, değer tabanlı, yeni ürünlere yönelik ve diğer fiyatlandırma stratejileridir. Aşağıdaki kısımlarda bu fiyatlandırma stratejileri turizm işletmeleri yönünden incelenmektedir.

- Mal veya Hizmetin Maliyetine Dayanan Fiyat Belirleme Stratejisi: Maliyete dayalı fiyatlandırma, talebe dayalı fiyatlandırmaya göre çok daha kolay uygulanan fiyatlandırma stratejisidir (Mucuk, 2004, s.157). Bu yöntem ile üretimin maliyetlerinin hesaplanması, birim üretim veya hizmet sonucu oluşan maliyetin tespit edilmesidir. Maliyetlere ilişkin veriler iç kaynaklı olduğundan hesaplanması kolaydır. Maliyet merkezli fiyatlandırma stratejisinde turizm işletmeleri sadece üretim maliyetlerini dikkate almaktadirlar.

- Talebe Dayalı Fiyat Stratejisi: Talebe dayalı fiyat stratejisinde, maliyetleri değil, müşterilerinin turizm sektöründeki ürünle alakaları değerlendirmeleri esas alınmaktadır. Talebe dayalı fiyat stratejisinde, müşterilerin istekleri ve ihtiyaçlarını karşılayabilmek için turistik ürüne ne kadar ödemeye istekli olunduğu tahmin edilmeye çalışılır (Cravens ve Piercy, 2003, s.393). Bu nedenle bir mal ya da hizmetin fiyat kararı verilmeden önce pazarlama yöneticisi fiyat ve talep arasındaki ilişkiyi anlamalıdır (Gross ve Peterson, 1987, s.441). Bir mal ve hizmet için tüketicilerin alternatif fiyatlara verecekleri tepkileri ortaya koymak stratejik bir karar olan fiyatın belirlenmesi acısından önemlidir (Cravens ve Piercy, 2003, s.379). 
- Rekabete Dayalı Fiyatlandırma Stratejisi: Rekabet dayalı fiyatlandırma stratejisinde, maliyetler ve talepten çok, turizm pazarında faaliyet gösteren rakiplerin fiyatları göz önünde tutulmaktadır. Turizm işletmesinin rakiplerinin fiyatların baz alarak fiyatlandırma yapılmaktadır. Aynı fiyatlandırma düzeyinin belirlenebileceği gibi piyasanın koşulları ve yapısına oranla daha düşük veya yüksek bir fiyatlandırma yapılabilmektedir.(Yükselen, 2010, s.275). Gerçek hayatta görülen fiyatlandırma stratejileri içerisinde, turizm alanındaki işletmeler içinde uygulanabilirliği en kolay yöntem olarak bilinmektedir. Çünkü, yöntem talep tahminleri, talebin fiyat elastikiyeti gibi tespiti zor olan unsurları dikkate almamaktadir.

- Değer Tabanlı Fiyatlandırma Stratejisi: Geleneksel fiyatlandırma yöntemleri; maliyete göre fiyatlandırma, talebe göre fiyatlandırma ve rekabete dayalı fiyatlandırmadan oluşmaktadır. Her üç yöntem de, tüketicinin ürüne verdiği değerin parasal karşılığını dikkate almamaktadır. Oysaki değer temelli fiyatlandırma ürünün; maliyetine, pazara ya da rakiplere göre fiyatını belirlemek yerine, tüketicinin ürüne verdiği değere göre belirleme stratejisi olarak ifade edilmektedir (Nagle ve Holden, 2002, s.2).

- Yeni Ürüne Dayalı Fiyat Belirleme Stratejisi: Turizm alanındaki işletmenin, pazara ilk defa arz edeceği ürünün taklit edilme tehlikesinin düşünülerek hareket edilmesi gerekir. Belirlenen strateji, rekabet durumunun, ürünün kalitesinin, fiyatlandırmanın amaçlarına göre değişiklik arz etmektedir. (Mucuk, 2004, s.167)

- Diğer Fiyatlandırma Stratejileri: İşletmelerin birden çok fiyatlandırma hedefleri bulunmaktadır. Turizm işletmeleri, bu hedefleri gerçekleştirebilmek için birden çok fiyatlandırma stratejilerine başvurmaktadırlar. Pazarlama literatüründe çok sayıda fiyatlandırma stratejisi incelenmektedir. Bunlar özel durumlara yönelik uygulanmakta olan, tutundurma yönlü fiyatlandırma, indirimli fiyatlandırma, psikolojik fiyatlandırma, coğrafi bölgelere göre fiyatlandırma ve dinamik fiyatlandırma stratejileri ele alınmaktadır.

\section{Turizm İşletmelerinde Fiyatlandırma Stratejisini Etkileyen Faktörler}

İşletmelerin fiyatlandırmada; sürekliliğini sağlama, finansal, pazar odaklı gibi amaçları bulunmaktadır. Sürekliliğini sağlama; temel amacı yaşamını 
sürdürmektir. Düşük fiyat belirleyerek satış artırılmaya çalışılmakta, kar ikinci planda olmaktadır. Kısa vadede sonuç alınabilen amaçlardandır (Kotler ve Armstrong, 2004, s.303).

Finansal olarak fiyatlamadaki amaç, ürün satışlarından gelecekte elde edilen karın bugünkü değerini maksimize etmektir. Bu nedenle işletmeler cari karın maksimizasyonunu amaç olarak seçmektedir. Fiyatlandırmadaki temel amaç, en yüksek karı veren fiyat düzeyinin belirlenmesidir (Mucuk, 2004, s.152).

Pazar odaklı fiyatlandırmadaki amaç ise pazar payında lider olmak istemeleridir. Bu nedenle işletmeler satışlarını artırmak ve pazar paylarını yükseltmek istemektedirler. Bu amaçla işletmeler mümkün olduğunca düşük fiyat belirlemektedir (Altunışık vd., 2006, s.97).

Turizm işletmeleri fiyatlandırma kararlarını belirlerken dikkate alınması gereken faktörler sadece satın alma gücü ve maliyet giderlerinden oluşmamaktadır. Turizm işletmelerinin fiyatlandırma kararlarını etkileyen faktörler aşağıdaki şekilde özetlenebilir:

- Maliyetler,

- Yasal faktörler,

- Rekabet,

- Pazar ve talep yapisi,

- Tüketici davranışları

- Dağıtım kanallarına bağlı faktörler,

- Mal ve hizmetlerin niteliği,

- Pazarlama karması stratejisi,

- Turizm işletmelerinin kuruluş yerleri.

İfade edilen bu kararların dikkate alınarak oluşturulan fiyat politikası işletmeleri piyasa koşullarında rekabet avantaji elde etmesini sağlayacaktır. İşletmeler daha etkin ve verimli faaliyetlerini sürdürebilmektedirler. Dolayısıyla işletmeler, kendi koşulları ve piyasa durumunu kıyaslayarak iç ve diş faktörleri de hesaba katarak fiyatlandırma stratejisini belirlemelidir.

\section{Turizm İşletmelerinde Fiyatlandırma Stratejileri ve Muhasebe Bilgi Kalitesi}

İşletmelerin küresel rekabet ortamında uzun süre varlığını sürdürebilmesi için pazarlama döngüsünün stratejik manada ve yeterli seviyede gerçekleştirilmesi olmazsa olmaz bir zorunluluktur. Bu durum neticesinde bilgi temelli 
rekabetin önemli hale geldiği görülmekte ve işletmelerin yenilikçi politikalar geliştirip ve stratejiler manada yeni yöntemler aramalarına sebebiyet vermektedir. Bunun gerçekleştirilmesi, güvenilir, uygulanabilir ve zamanında bilgi ile mümkün hale gelmektedir. Bu niteliklerden yoksun bilgi stratejik manada yanlış adımların atılmasına neden olmaktadır. Bu nedenlerden dolayı, eksik ve hatalı bilgilerle atılan yanlış adımların neden olduğu sorunların kısa süreçte alınacak olan pazarlama tedbirleriyle çözülememesi, stratejik pazarlamada bilgiyi yönetme sürecinin daha etkili kullanılmasını önemli hale getirmektedir. İşletmenin önemli işlevlerinden biri olan muhasebe ile pazarlama arasındaki etkileşimi güçlü hale getiren temel neden pazarlama sorularıdır. Stratejik sebeplerden doğan sorunların çözümünde de nicel ve nitel bilgilere ihtiyaç duyulmaktadır. Fonksiyonların birbirleriyle etkileşimli olarak çalışması ile ihtiyaç duyulan bilgilerin yeterli düzeyde karşılanmasını sağlayacaktır. Ancak, genel olarak stratejik anlamda pazarlama faaliyetleri için bilgi hazırlama işlevi Pazarlama Bilgi Sistemi (PBS) - Muhasebe Bilgi Sistemi (MBS) ilişkisi aracıllğıyla yerine getirilirken, özelde ise Stratejik Yönetim Muhasebesi (SYM)'nin amacına uygun olarak kullanılmasıyla yerine getirilebilmektedir.

Muhasebe ile pazarlamanın en ciddiyetle ele alınması gereken ortak alan fiyatlama konusu, stratejik fiyat politikalarından oluşması, fiyatlamada SYM'den elde edilen bilgiler temellendirilerek karara varılması gibi faktörler nedeniyle Pazarlama Muhasebesi (PM) kavramı ortaya çıkmaktadır. PM, pazarlamayı ilgilendiren bilgilerin toplanması, tüm çalışanlar ile paylaşılması, pazarlamanın satış ve lojistik maliyetlerinin hesaplanması şeklinde tanımlanmaktadır. Ayriyeten, müşteri lehine gözetme, markalaşma ve bu markanın değerlenmesini sağlama, bu değeri koruma, rekabete dayalı fiyatlama gibi araçlarla bilgi temelini oluşturmaktadır. Stratejik pazarlama kararlarının, çeşitlendirilmiş güvenli bilgi kaynaklarıyla desteklenmesinde, ilerleyen dönemdeki faaliyetlerin planlandırılması ve kontrol altında tutulmasında muhasebe departmanından elde edilen bilgilerden faydalanılmaktadır. Dolayısıyla doğru, geçerli ve kaliteli bir karar alınabilmesi için pazarlama bilgilerinin muhasebe bilgileriyle desteklenmesinde önemli fayda sağlamaktadır. $\mathrm{Bu}$ durum işletmelerde departmanlar arası (pazarlama, muhasebe, yönetim, üretim gibi) koordinasyon ve etkileşim sonucunda oluşmaktadır (Ceran ve Bezirci, 2011). 
İşletmelerin faydalandıkları bilgi sistemleri aracıllğıyla müşterileri ilişkilerinden faaliyet süreçlerine, pazara girme stratejilerinden performans değerlendirmesine kadar bütün alanlarda teknolojik imkanlardan faydalanarak bilgi yönetimi geliştirilirken, aynı zamanda da rekabet edebilme gibi bir yarar elde edilmektedir (Tekin vd., 2006, s.860). Pazarlama, iyi tanımlanmış bir pazarda müşteri ihtiyaçlarının, arzu ve isteklerinin analizi ve yapılan bu analize göre ihtiyaçların karşılanması ile gerçekleştirilen ürün geliştirme ve tasarımı, fiyatlandırma, tutundurma ve dağıtımıyla ilgili bütün faaliyetlerin planlanması ve uygulanması olarak tanımlanabilmektedir (Ülgen ve Mirze, 2006, s.283; Mirze, 2010, s.302).

Muhasebe ve pazarlama açısından fiyat politikası büyük önem taşımaktadır. Maliyet muhasebesi uygun bir biçimde minimum fiyatın hesaplanması ile yetinirken, pazarlamada fiyat politikası, fiyat yönetiminde geniş bir anlayış olarak ortaya çıkmaktadır. Fiyatlar, işletmelerde pazarlama sistemi içinde fiyatların belirlenmesinde temel olan maliyet muhasebesinden elde edilen bilgilerden faydalanılarak bağımsız bir şekilde kararlaştırılmaktadır (Ceran ve İnal, 2004, s.64). Fiyat politikasında karar almada muhasebe biriminden elde edilen bilgilerden faydalanılırken, minimum fiyat sınırın belirlemede satış gelirleri ve maliyetler pazarlama faaliyetleri üzerinde etkili olmaktadır (Rese, 2006, s.743-744). Minimum fiyat sınırı maliyete ve satış gelirlerine dayalı olarak belirlendiğinden, fiyat politikasında maliyet yüksekliği ve kalite de karar almada aşamasında etkili olmaktadır. Fiyatlandırma, hangi sektör, hangi mal veya hizmet, hangi pazar şartlarında olursa olsun en önemli pazarlama karması elemanı olarak karşımıza çıkmaktadır. Fiyat, müşteri tercihini etkileyen en önemli faktörlerden bir tanesidir. Turizm işletmesi açısından da karlılığı, büyümeyi ve gelişmeyi sağlayan önemli bir etkendir. Bu aç1dan piyasada rekabet edebilmek için muhasebe bilgileri önemli bir rol oynamaktadır. Muhasebe bilgilerinden oluşan yüksek kaliteli finansal raporlama, bilgi asimetrisini azalttığı, genel şeffaflığı artırdığı ve sözleşme süreçlerinde iyi bir araç görevi gördüğünden pazar açısından takdir görmektedir (Watts ve Zimmerman, 1986). Ayrıca daha yüksek kaliteli finansal raporlama: daha düşük öz sermaye maliyeti ve borç sermayesi (Francis vd., 2004), daha yüksek piyasa likiditesi (Diamond ve Verrecchia, 1991), daha iyi performans ve daha yüksek rekabet gücü avantajı sağlamaktadır. 


\section{Sonuç ve Öneriler}

Mal ve hizmetlerin üreticiden son tüketiciye doğru akışı, satış öncesi ve sonrası hizmetler, pazar araştırmaları, yeni ürün geliştirme, satış planlamaları, reklam ve tanıtım, fiyatlandırma stratejileri, satış analizleri ve minimum maliyet en yüksek müşteri memnuniyeti elde etme gibi işletme faaliyetlerine yönelik bilgileri üreten ve toplayan Pazarlama Bilgi Sistemi (PBS)'den beklenen pazarlama kararlarını etkin hale getirmesidir. PBS, ilgili yöneticilere stratejik bir bakış açısı kazandırarak pazarlama ile ilgili önemli kararlar almasını kolaylaştırmaktadır. Pazarlama yöneticilerinin ihtiyaç duyduğu satış yönetimi, pazarlama planlaması, tutundurma, satış tahmini, ürün yönetimi, reklam ve ürün, satış bölgesi, satıclara yönelik, geçmişteki, mevcut durum ve gelecekteki olası satışlar ile ilgili nakit akışları, maliyetler, stoklar, alacaklar ve borçlar gibi özel bilgiler ile rutin faaliyetler ile ilgili bilgiler, MBS tarafından hazırlanarak sunulmaktadır.

Stratejik pazarlama faaliyetlerine yönelik pazarlama sorunları yoğun bir şekilde ortaya çıkması ve bu sorunları üstesinden gelmek için faaliyetlerin temelini oluşturan ve etkileyen kararların sistematik olarak sağlam temellere dayandırılması için muhasebe yöntemleri aracılı̆̆ıyla desteklenmekte ve sorunun çözümü için Stratejik Pazarlama Muhasebesi (SPM)'den destek alınmaktadır. SPM, işletme faaliyetlerinin pazara yönelik ve etkinliği artıracak şekilde yönetilmesinde muhasebe biriminden kapsamlı bir şekilde faydalanma imkânı sunmaktadır. SPM'de, stratejik rekabet açısından yeni ürün geliştirme sürecinde maliyet yönetimi ve maliyet düşürme yaklaşımları olarak Stratejik Maliyet Yönetimi yaklaşımları olan Faaliyete Dayalı Maliyetleme, Kaizen Maliyetleme, Hedef Maliyetleme, Eşzamanlı Maliyetleme, Ürün Yaşam Seyri Maliyetleme, JiT Maliyetleme, Kalite Maliyetleme, Tedarik Zinciri Maliyetleme ve Lojistik Maliyetleme yöntemlerinden doğru bir stratejik ürün ve fiyat kararı alabilmek için faydalanılmaktadır.

SPM'nin, pazarlama yönetimi ve denetimindeki önemi nedeniyle, işletme yöneticilerinin pazarlama maliyetlerinin daha sağlıklı hesaplanması, analiz edilmesi, kontrolü, yönetimi, maliyet düşürme, verimli olmayan ürünlerin üretim hattından kaldırılması gibi konuları kapsayacak şekilde SPM'nin, MBS'nin bir unsuru olarak oluşturması, pazarlama bölümü, muhasebe bölümü ve işletmenin diğer fonksiyonları ile koordineli bir şekilde çalışmasını sağlayacak, birbirleriyle işbirliği içerisinde olacak şekilde işletme içinde ayrı 
bir sistem olarak oluşturması gerekmektedir. İşletmelerin de uluslararası rekabet ortamında rekabet edebilmek, pazarda sürekliliği sağlayabilmek ve varlığını devam ettirebilmek için muhasebe, maliyet muhasebesi, yönetim muhasebesi, stratejik yönetim muhasebesi uygulamalarına gereken önemi vermesi, stratejik pazarlama kararlarının alınmasında PBS ve MBS ilişkisi sonucunda oluşturulan SPM anlayışını benimsemeleri uygun ve yararlı olmaktadır.

Dolayısıyla, muhasebe uygulamasının değişen koşula intibak sağlayabilmesi için kısmi esneklik içerebilmektedir. Bu nedenden dolayı yöneticilerin işletmenin faaliyetlerinin sonuçlarının olduğundan farklı sunabilme olanağ sağlamaktadır. Fiyatlandırma vb. gibi manipülasyon durumları muhasebede bilginin niteliğini azaltarak finansal tablolardan faydalanan kullanıcıların ekonomik açıdan eksik veya hatalı kararlar vermelerine ve sonucunda ilgililerin menfi etkilere maruz kalmasına sebebiyet vermektedir. 


\title{
EXTENDED ABSTRACT
}

\section{The Relationship between Pricing Strategies and Accounting Information Quality in Tourism Enterprises}

\author{
Murat Karahan \\ Gaziantep University
}

For businesses to survive in a globally competitive environment for longer time, marketing activities are inevitably carried out strategically and at a sufficient level. In today's world where knowledge-based competition keenly prevalent, this situation causes the enterprises to develop new policies and strategies. And this can be made with reliable, appropriate and timely information. Information which does not contain these qualities can cause strategically wrong decisions. Therefore, the problems which caused by wrong decisions due to missing and incorrect information cannot be solved with shortterm marketing measures. Hence, it is important to manage and use information more effectively in strategic marketing. Information, which is used as a basic input in developed or developing economies, is the main source of organizations nowadays. Businesses with economic value need the information to achieve their goals. Accounting Information System (AIS) reflects the accounting aspect of business processes. Accounting Information System (AIS) can be expressed as a business information system that collects and records the data related to business activities and tries to provide the information they need to the internal and external information users in a quality manner by transforming the data into information.

Price, which is a marketing mix element, is also a vital competitive tool, but determining the pricing strategy and the appropriate price level in the tourism sector affects the business volume of the tourism business. Pricing in tourism businesses is determined in line with the objectives of the business. The purpose of pricing is part of the marketing planning of the tourism business. 
In tourism businesses, pricing strategies appropriate to the goals and objectives are determined. In terms of price strategies; Different situations can be applied, such as skimming the market and strategy to penetrate the market. In the pricing strategy of skimming the market, tourism markets are entered at the upper range prices. This strategy can be applied if the demands are strong and the products in tourism are widely differentiated (Lamb et al., 1994: 84). In the penetration pricing strategy, tourism companies aim to set a price below their competitors in the market and to have a voice in the market sections in a short time. (Friel, 1999, p. 101). For this strategy, consumers are sensitive to prices. If the demand is not sensitive to pricing, low pricing will not lead to an increase in demand. (Baker et al., 1998, p. 83).

The factors that should be taken into consideration when determining the pricing decisions of tourism establishments do not only consist of purchasing power and cost expenses. Factors affecting the pricing decisions of tourism companies can be summarized as follows:

- Costs,

- Legal factors,

- Competition,

- Market and demand structure,

- Consumer behavior

- Factors dependent on distribution channels,

- The nature of the goods and services,

- Marketing mix strategy,

- Establishment locations of tourism enterprises.

Price policy enterprises, which are formed by taking into account these stated decisions, will enable them to gain competitive advantage in market conditions. Businesses can continue their activities more effectively and efficiently. Therefore, businesses should determine their pricing strategy by comparing their conditions and market conditions, taking into account internal and external factors.

The concept of Marketing Accounting (PM) emerges due to factors such as the common area of pricing, which consists of strategic pricing policies, and the decision made based on the information obtained from Strategic Management Accounting. PM is defined as collecting information about marketing, sharing it with all employees, and calculating sales and logistics costs 
of marketing. The information obtained from the accounting department is used to support strategic marketing decisions with diversified sources of secure information, and to plan and keep control of future activities. Therefore, it provides significant benefits in supporting marketing information with accounting information in order to make a correct, valid and quality decision. This situation occurs as a result of coordination and interaction between departments (such as marketing, accounting, management, production) in businesses (Ceran and Bezirci, 2011).

Pricing is the most important marketing mix element, regardless of the sector, which goods or services, and what market conditions. Price is one of the most important factors that affect customer preference. It is also an important factor that ensures profitability, growth and development in terms of tourism business. In this respect, accounting information plays an important role to compete in the market. High quality financial reporting, consisting of accounting information, is appreciated for the market as it reduces information asymmetry, increases overall transparency and serves as a good tool in contract processes (Watts and Zimmerman, 1986). Also, higher quality financial reporting: lower equity cost and debt capital (Francis et al., 2004), higher market liquidity (Diamond and Verrecchia, 1991), better performance and higher competitive advantage.

The aim of the research is to examine the importance of pricing in terms of tourism businesses and its relationship with accounting information quality.

As a result of this study, due to the importance of Strategic Marketing Accounting in marketing management and control, Strategic Marketing Accounting, Accounting Information System, covering issues such as calculating, analyzing, controlling, managing, reducing costs, removing the inefficient products from the production line more effectively. It should be created as a separate element, it should be created as a separate system within the enterprise, which will work in a coordinated manner with the marketing department, accounting department and other functions of the business, and in cooperation with each other. In order to compete in an international competitive environment, to ensure continuity in the market and to maintain its existence, businesses give the necessary importance to accounting, cost accounting, management accounting, strategic management accounting practices, and the Strategic Marketing Accounting understanding created as a result of 
the relationship between Marketing Information System and Accounting Information System. it is appropriate and useful for them to adopt. It is stated that pricing strategies and accounting information quality are affected by each other and should be handled as a whole.

\section{Kaynakça / References}

Acar, D. ve Tetik, N. (2005). Genel muhasebe. (Gözden Geçirilmiş 4.Baskı). Ankara:Detay Yayıncllı.

Altunışık, R., Özdemir, Ş. ve Torlak, Ö. (2006). Pazarlamaya giriş. Adapazarı:Sakarya Yayıncllk.

Artar, A. (1999). İşletmelerin stratejik yönetim sürecinde fiyatlandırma kararları. Ankara:Milli Prodüktivite Merkezi Yayınları. No:639.

Baker, S., Braddley, P. ve Huyton, J. (1998). Principles of Hotel front office operations. London:Cassel.

Beatty, A.; Liao, W.S. ve Weber, J. (2010). The effect of private information and monitoring on the role of accounting quality in investment decisions. Massachusetts Institute of Technology Working Paper, 27(1). 17-47.

Callen, J.L., Khan, M. ve Lu, H. (2013). Accounting quality, stock price delay, and future stock returns. Contemporary Accounting Research, 30(1), 269-295.

Ceran, Y. ve Bezirci, M. (2011). Pazarlama bilgi sistemi:Muhasebe bilgi sistemi ilişkisine stratejik bir yaklaşım: Stratejik pazarlama muhasebesi. Selçuk Üniversitesi Sosyal Bilimler Enstitüsü Dergisi, 26, 103-115.

Ceran, Y. ve İnal, M.E. (2004). Maliyet bilgileri temeline dayalı pazarlama kararları için pazarlama muhasebesi. Erciyes Üniversitesi İ.I.B.F. Dergisi, 22, 6383.

Cravens, D.W. ve Piercy, N.F. (2003). Strategic marketing. 7th Edit. Boston:McGraw-Hill/Irwin.

Dechow, P.M. ve Schrand, C. (2004). Earnings quality. USA: The Research Foundation of CFA Institute.

Diamond, D.W. ve Verrecchia, R.E. (1991). Disclosure, liquidity, and the cost of capital. The Journal of Finance, 46(4), 1325-1359.

Doğan, A., Tanç A. ve Tanç, G.Ş. (2004). Felaketten kurtarma planı ve muhasebe bilgi sitemi: Kayseri'deki Büyük ölçekli sanayi işletmeleri üzerine bir araştırma. 3.Ulusal Bilgi, Ekonomi ve Yönetim Kongresi, 25-26 Kasım, Eskişehir.

Drucker, P.F. (1999). Bilgi yönetimi. (Çeviren Bulut G.). İstanbul:MESS Yayınları. 
Fidan, H. (2009). Pazarlama bilgi sistemi (PBS) ve Coğrafi bilgi sistemi (CBS)'nin pazarlamada kullanımı. Journal of Yaşar University, 4(14). 2151-2171.

Francis, J., LaFond, R., Olsson, P.M. ve Schipper, K. (2004). Cost of equity and earnings attributes. The Accounting Review, 79(4), 967-1010.

Friel, M. (1999). Marketing practice in small tourism and hospitality firms. International Journal of Tourism Research, 1, 97-109.

Gençoğlu, Ü.G. ve Ertan, Y. (2012). Muhasebe kalitesini etkileyen faktörler ve Türkiye'deki durum. Muhasebe ve Finansman Dergisi, 53,1-24.

Gross, C.W. ve Peterson, R.T. (1987). Marketing: Concepts and decision making. St. Paul:West Publishing Company.

Hribar, P., Kravet, T. ve Wilson, R. (2014). A new measure of accounting quality. Review of Accounting Studies, 19, 506-538

Karayormuk, K. ve Köseoğlu, M.A. (2005). Pazarlama bilgi sistemi ve bir kamu kuruluşu örneği. Afyon Kocatepe Üniversitesi İ.I.B.F. Dergisi. 7(2). 103-121.

Kotler, P. ve Armstrong, G. (2004). Principles of marketing. 10th Edition. New Jersey:Upper Saddle River. NT: Prentice Hall.

Kotler, P. (2003a). Marketing management, analysis, planning and control. 11th Edition. New Jersey:Prentice Hall..

Kwapil, C., Baumgartner, J. ve Scharler, J. (2005). The price-setting behaviour of Austrian firms: Some survey evidence. European Central Bank Working Paper Series. No: 464. March.

Lamb, C.W., Hair, J.F. ve McDaniel, C. (1994). Principles of marketing. Ohio:SouthWestern Publishing Co.

Mirze, S.K. (2010). İşletme. 1. Basım. İstanbul:Literatür Yayıncılık.

Mucuk, İ. (2004). Pazarlama ilkeleri. Türkmen Kitabevi.

Nagle, T.T. ve Holden, R.K. (2002). The strategy and tactics of pricing: A guide to profitable decision making. 3rd Edition. Upper Saddle River. NJ: Prentice Hall.

Pounder, B. (2013). Measuring accounting quality. Strategic Finance, 95(5), 18-20.

Rese, M. (2006). Marketing accounting. handbuch marketing-controlling:2. Auflage. Ed; S. Reinecke und T. Tomczak. Betriebswirtschaftlicher Verlag içinde (s.741-766), Dr. Th. Gabler-GWV Fachverlage GmbH. Wiesbaden.

Rızaoğlu, B. (2004). Turizm pazarlaması. 4. Baskı. Ankara:Detay Yayıncılık.

Romney, M.B. Steinbart P.J. ve Cushing, B.E. (1997). accounting information systems. 7th Edit, Addision-Wesley Publishing Company.

Sürmeli, F., Erdoğan, M., Erdoğan, N., Banar, K., Kaya, E. ve Sevim, A. (2006). Muhasebe bilgi sistemi. Eskişehir:T.C. Anadolu Üniversitesi Yayını. No:1644. 
Tekin, M., Çiçek, E.; Göbenez, Y. ve Bay, M. (2006). Bilgi yönetiminin işletmelerde rekabetçi üstünlük sağlama konusundaki önemi ve Karaman gida sanayisinde bir uygulama. Ed; G. Gençyılmaz, ÜAS'06 VI. Ulusal Üretim Araştırmaları Sempozyumu Bildiriler Kitabı. İçinde (s.857-866), 22-23 Eylül 2006. İstanbul:İstanbul Kültür Üniversitesi Yayınları-56.

Torlak, Ö. (1997). İmalatçı işletmelerde pazarlama problemleri ve alternatif pazarlama stratejileri. Dünden Bugüne Adapazarı Sempozyumu. Sakarya Üniversitesi İBF-Adapazarn Ticaret ve Sanayi Odası. 205-217.

Ülgen, H. ve Mirze, S.K. (2006). İşletmelerde stratejik yönetim. (3. Bsm). İstanbul:Literatür Yayıncllk.

Verdi, R.S. (2006). Financial reporting quality and investment management. Massachusetts Institute of Technology Working Paper.

Wang, R.Y. ve Strong, D.M. (1996). Beyond accuracy: What data quality means to data consumers. Journal of Management Information Systems, 12(4), 5-33.

Watts, R. ve Zimmerman, J. (1986). Positive accounting theory. Edgewood Cliffs. NJ: Prentice Hall.

Yükselen, C. (2010). Pazarlama ilkeleri-yönetim-örnek olaylar. 8. Bsm. Ankara:Detay Yayıncilik.

\section{Kaynakça Bilgisi / Citation Information}

Karahan, M. (2020). Turizm işletmelerinde fiyatlandırma stratejileri ve muhasebe bilgi kalitesi ilişkisi. OPUS-Uluslararası Toplum Araştırmaları Dergisi, 15(26), 4665-4685. DOI: 10.26466/opus.716496 